
\title{
25 Research Soure \\ Morbidity profile and prevalence of diabetes and high blood pressure among truck drivers in three regions of India
}

\section{Sonali Randhawa}

Piramal Swasthya Management and Research Institute

Vishal Dogra ( $\sim$ vishal.dogra@piramalswasthya.org)

Piramal Swasthya Management and Research Institute https://orcid.org/0000-0001-9725-5699

Hardeep Singh Bambrah

Piramal Swasthya Management and Research Institute

Shailendra Hegde

Piramal Swasthya Management and Research Institute

Ajit Kisanrao Sudke

Piramal Swasthya Management and Research Institute

Vishal Phanse

Piramal Swasthya Management and Research Institute

Research article

Keywords: Health morbidities, truck driver, India

Posted Date: November 19th, 2020

DOI: https://doi.org/10.21203/rs.2.12894/v2

License: () (1) This work is licensed under a Creative Commons Attribution 4.0 International License.

Read Full License 


\section{Abstract}

Background Truck drivers in India are one of the groups experiencing a disproportionate health burden. Understanding the distribution of morbidities is essential to plan and mitigate the risk of premature mortality among this subgroup. Paperaims to describe the health morbidities and prevalence of diabetes and high blood pressure among truck drivers in three regions of India.

Methods Data were routinely collected from a community-based healthcare program for truck drivers. Electronic medical health records (July 2018 to February 2019) of truck drivers were accessed and analyzed. The sociodemographic, health risk and morbidity profile of the truck drivers with an emphasis on diabetes, and high blood pressure in East, West, and South, regions of India were studied. Significance level was reported at p-values less than 0.05 .

Results A total of 15725 truck drivers were identified, of which 10247 (65\%) were from the south region alone. Majority of truck drivers were male and middle-aged (median age 44 years). Over two-third (>62\%) truck drivers in all regions were tobacco users. Half of the truck drivers reported smoking in the South (53\%) compared to smokeless tobacco use in the West (53\%) and East (41\%) regions. Alcohol use alone and both alcohol and tobacco use were significantly lower in the West $(23 \%, 15 \%)$ compared to the East $(51 \%, 50 \%)$ and South $(68 \%, 52 \%)$ regions.

A significant number of truck drivers were either overweight 3485 (22\%) or obese 6772 (49\%). The prevalence of obesity among truck drivers ranged $55 \%$ in the South and $47 \%$ in the East compared to $32 \%$ in the West region. Of all truck drivers, 6991 (44\%) had non-communicable diseases; 3350 (21\%) had musculoskeletal conditions, and 1954 (12\%) were suffering from communicable diseases. The prevalence of diabetes differed significantly in the three regions $(\mathrm{p}<0.05)$. Nearly half of the truck drivers (7326/15725) 47\% had high blood pressure ( $\geq 140 / 90 \mathrm{~mm} \mathrm{Hg}$ ) and regional differences were not significant.

Conclusions Truck drivers in India suffer from multiple health and lifestyle-related diseases. Early identification of high risk and tailored behavioral and occupational interventions are needed urgently.

\section{Background}

The logistics sector is one of the key sectors contributing to the economic development in India. As per an estimate, this sector is expected to become a $\$ 215$ billion industry employing 40 million people by 2020 $(1,2)$. Among all modes of logistics, the contribution of road transport is highest $(60.2 \%)$ compared to railways $(32.1 \%)$, major port coastal shipping $(7.4 \%)$ and inland waterways transportation $(0.2 \%)(3,4)$.

Truck drivers in India are the leading players in the road transport market. Nearly five million truck drivers drive twelve hours on an average per day on an extensive spread of national highways (2). However, most of the times, they work in informal and unorganized settings with minimal attention to self-health. Compared to the general population, truck drivers experience higher on-the-job morbidity and mortality 
besides increased risk for sexually transmitted infections, metabolic syndromes, and cardiovascular diseases (5-9).

A few studies have evaluated the health and morbidity profile among Indian truck drivers. Existing literature have documented the prevalence of common health problems such as as hypertension (46\%), overweight (31\%), visual problems (17\%) (10), diabetes (13\%), (11) and lower back pain (62\%) (12) among Indian truck drivers. However, these studies have used a small convenience sample from around their geopgraphies, scattered in scope, and lack generalizability $(10,12)$. Besides, all these studies have focussed on sexual health or ergonomics conditions or assessing of the truck drivers knowledge and awareness on key health conditions $(10,12-14)$. Moreover, the existing literature discussing the prevalence of diabetes, hypertension, and associated risk factors among truck drivers are mostly from developed countries $(5,15,16)$. Hence, the present study fulfils an important literature gap to document health morbidities among truck drivers and assesss the differences in this group of population in three different regions of India.

Piramal Swasthya Management and Research Institute (PSMRI)- a national Non-Government Organization, in 2017, launched a community based mobile medical unit (MMU) health program. Initiated in partnership with Shriram Transport Finance Company Limited (STFCL), the program provides basic primary care services to truck drivers, their families, and helpers, jointly referred to as program beneficiaries, on major national highways of the country. Onwards, henceforth, we will call this program, "STFC-MMU." The STFC-MMU program design and service delivery offer a unique opportunity to study the changing health problems of truck drivers and helpers in India

\section{Aim}

We aimed to describe the socio-demographic, health risk, and morbidity profile among truck drivers availing the STFC-MMU program services with focus on prevalence of diabetes and high blood pressure

\section{Methods}

\section{Study Design and Settings}

In the present paper, we present a secondary analysis of routinely collected STFC-MMU program data. The program currently operates in 22 cities (program locations) across 12 states of India. In each city, a particular MMU covers specific program service sites (average 11 per site). The program service sites are selected based on truck driver's density, closeness to major national highways, and after discussion with truck union leaders and the respective state governments. Figure 1 gives an overview of the program locations in different states. For analysis purpose, we divided program locations into three regions namely East (Odisha, Bihar, Assam, Jharkhand \& West Bengal), West (Maharashtra, Gujarat \& Rajasthan), and South (Karnataka, Tamil Nadu, Andhra Pradesh \& Telangana).

\section{STFC-MMU Program Description}


The scope of STFC-MMU program is to provide beneficiaries preventive (screening for diabetes and hypertension through random blood glucose and blood pressure monitoring, and oral precancerous conditions), promotive (counseling on life-style related, and locally prevalent diseases including sexually transmitted diseases chiefly HIV \& AIDS), diagnostic (urine albumin, haemoglobin and malaria testing), curative (treatment for minor ailments, injuries, including illnesses such as diarrhoea and acute respiratory infections) and referral services (for complicated and high risk cases). PSMRI manages the design and implementation of the program while the STFCL provides funds to deliver the health care services to truck drivers. The program has two essential elements: physical and operational.

\section{Physical Elements}

Manpower: Each MMU has four staff members (Medical doctor, nurse, pharmacist, and driver). The role of the doctor is to provide preventive, promotive, curative care and referral services; nurse takes care of registration, captures the anthropometrics, basic lab testing, and assists doctor; pharmacist maintains the drug inventory, dispenses medicine, and responsible for data entry and management. The driver takes care of the vehicle and accompanies other staff members.

Equipment: Every vehicle is equipped with essential medicines and medical equipment such as digital blood pressure machine, glucometer, thermometer, weighing and height meter scale and torchlights to perform simple clinical investigations. Also, each MMU has an internet-enabled tablet and a preloaded software application for data collection and documentation purpose.

\section{Operational Elements}

Field Operations: All MMUs operate 24 days (Monday to Saturday; 10.00 AM to 5:00 PM) in a month. Every day, each MMU visit two program service sites (morning and evening) as per fixed-day service delivery schedule and pre-defined route maps. On a routine day, MMU nurse registers the beneficiary using software application and records their basic demographics, vitals, anthropometrics, biochemical, and clinical parameters. Next, the doctor performs the routine physical examination, prescribe laboratory tests as needed, and diagnose the health problems. The doctor then either prescribe the required medicine or refer the beneficiary to the next level of the healthcare facility as per assessed need. The doctor also counsels the beneficiary to maintain a healthy lifestyle.

In the next counter, a pharmacist dispenses the prescribed medicines free of cost based on the doctor's prescription. The pharmacist also manages the drug and data inventory of his MMU. Finally, nurse and pharmacist enter the beneficiary data using software application, synced daily on to centrally placed data servers. Figure 2 describes the services flow on any day.

\section{Analytical Frame for Analysis}

We accessed and analyzed routinely collected health records of truck drivers who availed STFC-MMU program services between July 2018 to February 2019. Variable filters such as age range (15 to 75 years), body mass index range (10 to $75 \mathrm{~kg} / \mathrm{square}$ meter) random blood sugar ranges (40 to $600 \mathrm{mg} / \mathrm{dl}$ ) 
were applied considering possible theoretical values of medical metrics (17-19). Figure 3 explains the procedure for calculating the final analytical frame.

\section{Inclusion Criteria}

The analysis was restricted to routinely collected health records of truck drivers, defined as "someone who drives the heavy/medium/small truck" and is utilizing STFC-MMU program services. The data include variables and information of the truck driver captured on their first visit to MMU.

\section{Exclusion Criteria}

Health records of helpers, support staff, or family member of the truck drivers.

\section{Variables, Definitions, and Measures}

From the final set of routine health records, we extracted the data on demographics (age, sex, marital status, and occupation), habits (tobacco and alcohol consumption), anthropometric measures (height, weight), clinical parameters (blood pressure and random blood sugar) and types of health problems. Health problems among truck drivers were either self-reported or diagnosed on-site by MMU doctor during their first consultation visit.

We used "Systematized Nomenclature of Medicine-Clinical Terms (SNOMED CT)" for consultation classification (20). We classified consultations further into six problem categories:

1. The non-communicable disease (NCDs) includes diabetes mellitus, hypertension, asthma, cataract, chronic obstructive pulmonary disease (COPD), and acid peptic disease

2. Musculoskeletal problems include arthralgia, arthritis, injury/trauma, myalgia, and osteoarthritis

3. Communicable diseases include acute bronchitis, acute diarrhea, acute rhinitis, amebiasis, conjunctivitis, dengue fever, dysentery, gastroenteritis, giardiasis, influenza (flu), lower respiratory tract infection, malaria, otitis media, pharyngotonsillitis, sinusitis, typhoid fever, urinary tract infection, viral fever, viral hepatitis and worm infestation

4. Skin problems include allergic rash, boils, fungal infections, impetigo, pyoderma, scabies, and wounds

5. Problems related to the oral cavity include aphthous ulcers, dental caries, dental fluorosis, febrile blisters, gingivitis, glossitis, gum abscess, oral ulcers, and stomatitis \& cheilitis

6. Other category includes anything not specified as above

We used standard definitions of body mass index for Asian Indians for risk profiling (17). Random blood sugar (RBS) values were categorized into "Normal" (RBS < $140 \mathrm{mg} / \mathrm{dl}$ ); "Impaired glucose level"( RBS between $140-199 \mathrm{mg} / \mathrm{dl}$ ) and "Diabetic" (RBS $\geq 200 \mathrm{mg} / \mathrm{dl}$ ) with classic symptoms of hyperglycemia" (21). National Family Health Survey-4 definitions for "Normal" (Systolic $<140 \mathrm{~mm} \mathrm{Hg}$ and/or Diastolic $<90$ mm Hg); "Slightly above normal” (Systolic 140-159 mm Hg and/or Diastolic 90-99 mm Hg); "Moderately 
high" (Systolic 160-179 mm Hg and/or Diastolic 100-109 mm Hg) and "Very high" (Systolic $\geq 180 \mathrm{~mm} \mathrm{Hg}$ and/or Diastolic $\geq 110 \mathrm{~mm} \mathrm{Hg}$ ) were used for blood pressure categorization (22).

\section{Statistical Analysis}

We report central frequency measures (mean, median, standard deviations) for continuous variables and frequency percentages for categorical variables. Chi-square and analysis of variance tests were used. Significance level at p-values less than 0.05 was considered. For the analytical purpose, we used the Statistical Package for Social Science version 25 (23).

\section{Results}

A total of 15,725 health records of truck drivers had complete data. Region-wise, South had the highest (65\%) numbers of truck drivers records compared to the West (23\%) and East (12\%). The average age of truck drivers in the three regions did not differ significantly (mean 44 years). Almost all truck drivers were married (98.4\%) and males (99\%). Nearly two-thirds male driver (62.4\%) were taking tobacco in any form, highest in the East region (76\%). Smoking was high among truck drivers of South (53\%) and East (30\%) region while smokeless tobacco consumption was high in the West (53\%) and East (41\%). Nearly $7 \%$ of truck drivers in the West region were both smokers and smokeless tobacco users. More than half (56\%) of the truck drivers reportedlywere consuming alcohol and little less than half $(43 \%)$ were consuming both alcohol and tobacco.

The mean BMI of truck drivers in three regions did not differ significantly $(25.2, S D \pm 4.32)$. A significant number of truck drivers were either overweight $(22 \%)$ or obese $(49 \%)$, and only one-fourth $(25 \%)$ had normal BMI. High obesity rates were observed in the South (76\%) and East (70\%). Table 1 summarizes the region-wise sociodemographic and risk factors profiling of the truck drivers.

Table 1: Sociodemographic and risk profile of truck drivers in East, West and South India (2018-2019) 


\begin{tabular}{|c|c|c|c|c|c|}
\hline Regions & $\begin{array}{r}\text { East } \\
(\mathrm{N}=1866) \\
(12 \%)\end{array}$ & $\begin{array}{r}\text { West } \\
(\mathrm{N}=3612) \\
(23 \%)\end{array}$ & $\begin{array}{r}\text { South } \\
(\mathrm{N}=10247) \\
(65 \%)\end{array}$ & $\begin{array}{r}\text { Total } \\
(\mathrm{N}=15725) \\
(100 \%)\end{array}$ & p-value \\
\hline Age (years) (Mean, & $(449.6)$ & $(469.4)$ & $\left(\begin{array}{lll}43.5 & 10\end{array}\right)$ & $\left(\begin{array}{ll}44 & 9.9\end{array}\right)$ & \\
\hline Male & 1856 (99.5) & 3571 & 10157 & 15584 & 0.07 \\
\hline Female & $10(0.5)$ & $41(1.0)$ & $90(1.0)$ & $141(1.0)$ & \\
\hline Marital Status & & & & & \\
\hline Married & $1850(99.0)$ & $\begin{array}{r}3545 \\
(98.0)\end{array}$ & $\begin{array}{l}10057 \\
(98.1)\end{array}$ & $\begin{array}{l}15452 \\
(98.4)\end{array}$ & 0.01 \\
\hline Single & $14(0.8)$ & $52(1.6)$ & $164(1.6)$ & $230(1.5)$ & \\
\hline Separated/Widower & $2(0.2)$ & $14(0.4)$ & $26(0.3)$ & $43(0.3)$ & \\
\hline Tobacco use (Yes) & $1424(76.0)$ & $\begin{array}{r}2280 \\
(63.0)\end{array}$ & $6116(60.0)$ & $9820(62.4)$ & 0.00 \\
\hline Smoke & $566(30.0)$ & $125(3.3)$ & $5378(52.5)$ & 6069 (38.6) & \\
\hline Smokeless & $758(41.0)$ & $\begin{array}{r}1914 \\
(53.0)\end{array}$ & $559(5.5)$ & $3231(20.5)$ & \\
\hline Both & $100(5.0)$ & $241(6.7)$ & $179(2.0)$ & $520(3.3)$ & \\
\hline Alcohol use (Yes) & 946 (51.0) & $835(23.0)$ & 7012 (68.0) & $8793(56.0)$ & 0.00 \\
\hline $\begin{array}{l}\text { Tobacco \& Alcohol } \\
\text { use }\end{array}$ & $932(50.0)$ & $533(15.0)$ & $5346(52.0)$ & $6811(43.0)$ & \\
\hline BMI (Mean, SD) & $\left(\begin{array}{ll}25.2 & 4.2\end{array}\right)$ & $(23.7 \quad 4.1)$ & (25.8 4.2) & $\left(\begin{array}{ll}25.2 & 4.3\end{array}\right)$ & 0.00 \\
\hline Underweight & $49(2.0)$ & $276(7.6)$ & $258(2.0)$ & $583(4.0)$ & \\
\hline Normal & $515(28.0)$ & $\begin{array}{r}1285 \\
(35.6)\end{array}$ & $2185(22.0)$ & 3985 (25.0) & \\
\hline Overweight & $426(23.0)$ & $901(25.0)$ & $2158(21.0)$ & $3485(22.0)$ & \\
\hline Obese & $876(47.0)$ & $\begin{array}{r}1150 \\
(32.0)\end{array}$ & 5646 (55.0) & $7672(49.0)$ & \\
\hline
\end{tabular}

Non-communicable diseases (44\%) and musculoskeletal conditions (21\%) were the top two observed morbidities. NCDs, communicable, and musculoskeletal conditions were the dominant health morbidities in the South and West regions, respectively. Table 2 summarizes the distribution of health morbidities among truck drivers in different regions.

Table 2: Distribution of health problems among truck drivers in East, West and South India (2018-2019) 


\begin{tabular}{|c|c|c|c|c|}
\hline \multirow{2}{*}{$\begin{array}{l}\text { Health problem } \\
\text { consultations for }\end{array}$} & \multicolumn{4}{|c|}{ Regions } \\
\hline & $\begin{array}{r}\text { East } \\
(\mathrm{N}=1866)\end{array}$ & $\begin{array}{r}\text { West } \\
(\mathrm{N}=3612)\end{array}$ & $\begin{array}{r}\text { South } \\
(\mathrm{N}=10247)\end{array}$ & $\begin{array}{r}\text { Tota } \\
(\mathrm{N}=15725)\end{array}$ \\
\hline & n (\%) & $\mathrm{n}(\%)$ & n (\%) & n (\%) \\
\hline${ }^{1}$ Non Communicable & $773(41.0)$ & $1224(34.0)$ & $4994(49.0)$ & $6991(44.0)$ \\
\hline${ }^{2}$ Musculoskeletal conditions & $122(7.0)$ & $866(24.0)$ & $2362(23.0)$ & $3350(21.0)$ \\
\hline${ }^{3}$ Communicable diseases & $83(4.0)$ & $585(16.0)$ & $1286(13.0)$ & $1954(12.0)$ \\
\hline${ }^{4}$ Skin diseases & $46(2.5)$ & $169(5.0)$ & $430(4.0)$ & $645(4.0)$ \\
\hline $\begin{array}{l}{ }^{5} \text { Problems related of Oral } \\
\text { cavity }\end{array}$ & $10(0.5)$ & $27(1.0)$ & $144(1.0)$ & $181(1.0)$ \\
\hline${ }^{6}$ Other category & $832(45.0)$ & $741(20.0)$ & $1031(10.0)$ & $2604(17.0)$ \\
\hline \multicolumn{5}{|c|}{$\begin{array}{l}{ }^{1} \text { Non-communicable diseases: Asthma, Cataract, COPD, Diabetes Mellitus, Hypertension and } \\
\text { Diabetes Mellitus \& Hypertension both. }\end{array}$} \\
\hline \multicolumn{5}{|c|}{$\begin{array}{l}{ }^{2} \text { Musculoskeletal problems include Arthralgia, Arthritis, Injury/Trauma, Myalgia and } \\
\text { Osteoarthritis }\end{array}$} \\
\hline \multicolumn{5}{|c|}{$\begin{array}{l}{ }^{3} \text { Communicable diseases: Acute Bronchitis, Acute Diarrhoea, Acute Rhinitis, Amebiasis, } \\
\text { Conjunctivitis, Dengue Fever, Dysentery, Gastroenteritis, Giardiasis, Influenza (Flu), Lower } \\
\text { Respiratory Tract Infection, Malaria, Otitis Media, pharyngotonsillitis, Sinusitis, Typhoid } \\
\text { Fever, Urinary Tract Infection, Viral Fever, Viral Hepatitis, and Worm Infestation }\end{array}$} \\
\hline \multicolumn{5}{|c|}{$\begin{array}{l}{ }^{4} \text { Skin problems: Allergic Rash, Boils, Fungal Infections, Impetigo, Pyoderma, Scabies and } \\
\text { Wounds }\end{array}$} \\
\hline \multicolumn{5}{|c|}{$\begin{array}{l}{ }^{5} \text { Problems related to the oral cavity: Aphthous Ulcers, Dental Caries, Dental Fluorosis, } \\
\text { Febrile Blisters, Gingivitis, Glossitis, Gum Abscess, Oral Ulcers, and Stomatitis \& Cheilitis }\end{array}$} \\
\hline${ }^{6}$ Other category: Anything & . & & & \\
\hline
\end{tabular}

Overall, $16 \%$ of the truck drivers had diabetes (random blood sugar level of $200 \mathrm{mg} / \mathrm{dl}$ or more with other classical symptoms), and the prevalence rates were significantly different in the three regions $(p<0.05)$. Significant proportions of truck drivers were pre-diabetic in the West compared to the other two regions. Almost half $(47 \%)$ of the truck drivers had raised blood pressure above normal. Approximately $4 \%$ of the truck drivers had both high RBS ( $>200 \mathrm{mg} / \mathrm{dl}$ ) and high blood pressure $(\geq 160 / 100 \mathrm{~mm} \mathrm{Hg})$. Table 3 describes region-wise variations in diabetes and high blood pressure prevalence rates.

Table 3: Prevalence of Diabetes \& high blood pressure among truck drivers in East, West and South India (2018-2019) 


\begin{tabular}{|c|c|c|c|c|c|}
\hline Health condition & & & Regions & & \\
\hline & $\begin{array}{r}\text { East } \\
(\mathrm{N}=1866)\end{array}$ & $\begin{array}{r}\text { West } \\
(\mathrm{N}=3612)\end{array}$ & $\begin{array}{r}\text { South } \\
(\mathrm{N}=10247)\end{array}$ & $\begin{array}{r}\text { Total } \\
(\mathrm{N}=15725)\end{array}$ & $\begin{array}{l}\mathrm{p}- \\
\text { value }\end{array}$ \\
\hline Diabetes (18) & $\mathrm{n}(\%)$ & $\mathrm{n}(\%)$ & n (\%) & n (\%) & 0.00 \\
\hline Normal (less than $140 \mathrm{mg} / \mathrm{dl}$ ) & $\begin{array}{r}1258 \\
(67.0)\end{array}$ & $\begin{aligned} 2594 \\
(72.0)\end{aligned}$ & $\begin{array}{r}6405 \\
(63.0)\end{array}$ & $\begin{array}{r}10257 \\
(65.0)\end{array}$ & \\
\hline $\begin{array}{l}\text { Impaired glucose level (between } \\
140-199 \mathrm{mg} / \mathrm{dl} \text { ) }\end{array}$ & $\begin{array}{r}270 \\
(15.0)\end{array}$ & $\begin{array}{r}617 \\
(17.0)\end{array}$ & $\begin{array}{r}2098 \\
(20.0)\end{array}$ & $\begin{array}{r}2985 \\
(19.0)\end{array}$ & \\
\hline Diabetic (more than $200 \mathrm{mg} / \mathrm{dl}$ ) & $\begin{array}{r}338 \\
(18.0) \\
\end{array}$ & $\begin{array}{r}401 \\
(11.0) \\
\end{array}$ & $\begin{array}{r}1744 \\
(17.0) \\
\end{array}$ & $\begin{array}{r}2483 \\
(16.0) \\
\end{array}$ & \\
\hline High Blood Pressure (19) & & & & & 0.79 \\
\hline Normal & $\begin{array}{l}1002 \\
(54.0)\end{array}$ & $\begin{array}{l}1947 \\
(54.0)\end{array}$ & $\begin{array}{r}5449 \\
(53.0)\end{array}$ & $\begin{aligned} 8398 \\
(53.0)\end{aligned}$ & \\
\hline Slightly above normal & $\begin{array}{r}525 \\
(28.0)\end{array}$ & $\begin{array}{l}1024 \\
(28.0)\end{array}$ & $\begin{array}{r}3026 \\
(30.0)\end{array}$ & $\begin{array}{r}4575 \\
(29.0)\end{array}$ & \\
\hline Moderately high & $\begin{array}{r}214 \\
(11.0)\end{array}$ & $\begin{array}{r}404 \\
(11.0)\end{array}$ & $\begin{array}{l}1116 \\
(11.0)\end{array}$ & $\begin{array}{l}1734 \\
(11.0)\end{array}$ & \\
\hline Very high & $125(7.0)$ & $237(7.0)$ & $656(6.0)$ & $1018(7.0)$ & \\
\hline $\begin{array}{l}\text { Diabetic \& High Blood } \\
\text { Pressure (Moderate and very high } \\
\text { blood pressure) }\end{array}$ & $84(4.5)$ & $93(2.6)$ & $450(4.4)$ & $627(4.0)$ & 0.00 \\
\hline
\end{tabular}

\section{Discussion}

To our knowledge, our study is the first large study in India describing health morbidities among truck drivers who are increasingly prone to lifestyle-related diseases. (15). Our analysis found truck drivers were suffering largely from lifestyle-related and musculoskeletal health conditions with a high prevalence of diabetes (16\%) and moderately and very high blood pressure (18\%). We observed mainly middle-aged male truck drivers who are disproportionally obese within regions could be due to irregular food habits and addiction to substance use, mainly tobacco and alcohol use as evident among this population. We observed the highest proportion of truck drivers records from the South (65\%) and few from the West $(23 \%)$ and East (12\%) region due to the fact the STFC-MMU program has more program service sites in the South region. Moreover, the program initiated early in the South region and recently expanded in the other two regions. We saw a majority of truck drivers in their late productive age group, which is no different, as found in other studies $(10-12,24)$

The prevalence of NCDs risk factors like tobacco (62.4\%) and alcohol (53\%) consumption were higher in our study compared to the existing literature $(10,25,26)$. Region-wise high consumption of alcohol and tobacco may be related to the easy availability of indigenous and raw products in East and West region where smokeless tobacco products such as gutkha, pan, and betel nuts are widely available and probably high net disposable income, education, and other social factors in the South $(27,28)$

Globally, it has been established that cardiovascular diseases are serious health issues among obese/overweight people with a sedentary lifestyle (29). As per guidelines, a BMI of $23.0 \mathrm{~kg} / \mathrm{m}^{2}$ or more reflects increased risk for Asian Indians for diabetes and cardiovascular diseases (17). The prevalence of 
obesity (a BMI of $25.0 \mathrm{~kg} / \mathrm{m}^{2}$ or more) among truck drivers (49\%) in our analysis was found to be nearly 2.5 times higher than the Indian male population $(18.9 \%)(22,26)$ Higher BMI could be because truck drivers who access our program services may have long driving hours, irregular eating habits, unhealthy lifestyle and irregular sleeping hours, leaving little or no time for exercise or healthy eating. The observed level of health morbidities, non-communicable diseases, and musculoskeletal conditions among Indian truck drivers are in agreement with existing Indian evidence (10-12) Besides, the physiological and occupational demands combined with long driving hours may explain the high prevalence of health morbidities (30).

In general, the prevalence of diabetes and high blood pressure among Indian truck drivers is higher compared to an adult Indian male from East, West, and South India $(26,31,32))$ The prevalence of high blood pressure (Systolic 140-159 mm Hg or more and/or Diastolic 90-99 mm Hg or more) among truck drivers (47\%) is nearly 1.5 times higher than the Indian male population (30.7\%) (33). Similarly the prevalence of diabetes (more than $200 \mathrm{mg} / \mathrm{dl}$ ) was 1.3 times higher in truck drivers (16\%) than the Indian male population (12\%) as documented by the National Diabetes and Diabetic Retinopathy Survey 2019 (34). However, within the regions, truck drivers from the West have slightly lower diabetes prevalence aligning with the findings of different survey reports documenting lower prevalence of diabetes among adults from the West region $(32,35)$. Regional variability of Indian diets may be a probable explanation for the high prevalence of diabetes in the southern region. Existing study has pointed that people in East and South regions are more likely to consume high-fat meal like meat, sweets, and snacks and hence carry a higher risk of diabetes and NCDs than those from the North and West India (36). Therefore, we can assume truck drivers from theseregions might have similar eating patterns and bear the same base risk as in the general population in addition to other risk factors. There is a possibility that increased level of random blood sugar and high systolic and diastolic blood pressure could put truck drivers at higher risk to lifestyle-related diseases in comparison to the general population.

To our knowledge, our study is the first large study in India which not only assessedthe health morbidities but also provide reliable information on diabetes and raised blood pressure estimates on a broader scale among truck drivers who are increasingly prone to lifestyle-related diseases. Therefore, the current study fills a significant knowledge gap and contributes to advancing scientific knowledge for this subgroup in a wide geographical area.

Although the present study broadens the understanding of morbidity and major NCDs prevalent among truckers in India; however, there are few limitations to it. First, the conventional data collection system could not capture the important predictor variables preventing us from making conclusions about the causative links between risk factors and truck driver's health profile. Second, the presence of high blood pressure is based on single blood pressure measurement recorded th the first visit only hence making it difficult to confirm the same as hypertension clinically. Third, the study sample included those truck drivers who availed STFC-MMU services. There is a possibility that nearby truck drivers have used the services frequently than those who are long-distance truck drivers. Additionally, we might have missed the truck drivers who were suffering from diabetes and or hypertension, but due to any reasons were not able 
to access the STFC-MMU services, thereby underreporting of the observed results. Finally, quantification and assessment of truck drivers taking hypoglycaemic drug or antihypertensive drugs before visiting the MMU was not done.

It is well known that truck drivers are a difficult group to engage in health and wellbeing initiatives $(8,37,38)$. Besides, a considerable gap exists between existing programmatic interventions to address the enormous NCDs burden under community settings. Therefore program interventions such as early screening, diagnosis, prompt treatment, and referral services for key NCDs are urgently required to reduce the NCDs related premature morbidity and mortality. Efforts like MMUs have the potential to deliver such interventions at scale. Studies exploring health truck drivers behaviors and health needs should be planned for designing tailored healthcare interventions.

\section{Conclusions}

Truck drivers in India suffer from a disproportionate burden of health morbidities. The high prevalence of lifestyle diseases such as diabetes and raised blood pressure increases the risk of premature mortality in this subgroup. Tailored healthcare interventions which focuses on the current health care needs and behaviors of the truck drivers are needed urgently promoting their overall well being.

\section{List Of Abbreviations}

PSMRI: Piramal Swasthya Management and Research Institute

MMU: Mobile Medical Unit

STFCL: Shriram Transport Financial Company Limited

BMl: Body Mass Index

RBS: Random Blood Sugar

NCDs: Non-Communicable Disease

\section{Declarations}

\section{Ethical approval and consent to participate}

Piramal Swasthya's Institutional Ethics Committee approved the study (IEC Study Ref No: PSMRI/2019/06).

\section{Consent for publication}

Program staff obtained beneficiary consent to use their anonymized data for research purpose. 
Availability of data and materials

We used routinely collected program data stored in centrally placed data servers. Data analyst extracted the data and anonymized it after removing all identifiable variables. The datasets analyzed during the current study are available on request from the corresponding author (vishal.dogra@piramalswasthya.org or vani1825@gmail.com).

\section{Competing interests}

The authors declare that they have no competing interests.

\section{Funding}

None. Authors were free to design, conduct, interpret, and publish this work without the involvement of the sponsor.

\section{Authors' contributions}

SR: Conceptualized the study, cleaned the data, performed data analysis and wrote first draft article VD: Conceptualized and designed the study. Guided overall analysis, critically revised all article versions and was a major contributor in manuscript writing HS: Supervised the data transfer from the STFC-MMU program database. Provided critical inputs in study design. SH \& AS provided inputs in the design and conduct of the study. All authors read and approved the final article version.

\section{Acknowledgments}

Authors are grateful to MMU field staff in providing services to the truck driver community. Thanks to Shriram Transport Financial Company Limited for financially supporting this program.

\section{References}

1. Ramachandran S, Mayur SN, Kumar P. Logistics in India: Challenges and Scope. International Review of Research in Emerging Markets and the Global Economy (IRREM). 2015;1(2):364-77.

2. India, KPMG C- I of L. Skill gaps in the Indian Logistics Sector: A white paper. 2007.

3. India G of, Finance M of, Affairs D of E. Economic Survey 2017-18. In: Government of India. 2018.

4. ICRA Management Consulting Services Limited IBEF. Indian Logistics Industry: Gaining MomentumA Report On The Performance And Emerging Trends In The Indian Logistics Industry. 2013;

5. Puhkala J, Kukkonen-Harjula K, Mansikkamäki K, Aittasalo M, Hublin C, Kärmeniemi P, Olkkonen S, Partinen M, Sallinen M, Tokola K FM. Lifestyle counseling to reduce body weight and cardiometabolic risk factors among truck and bus drivers - a randomized controlled trial. Scandinavian Journal of Work, Environment and Health. 2015;41(1):54-64. 
6. Alterman T, Li J, Petersen MR, Sestito J. Mortality Among Members of a Truck Driver Trade Association. American Association of Occupational Health Nurses, Inc JOurnal. 2010;58(11):47381.

7. Laden F, Hart JE, Smith TJ, Davis ME, Garshick E. Cause-Specific Mortality in the Unionized U.S. Trucking Industry. Environmental Health Perspectives. 2007;115(8):1192-6.

8. Lalla-edward ST, Ncube S, Matthew P, Hankins CA, Venter WDF, Gomez GB. Uptake of health services among truck drivers in South Africa: analysis of routine data from nine roadside wellness centres. BMC Health Services Research. 2017;17(649).

9. Varela-Mato V, O'Shea O, King JA, Yates T, Stensel DJ, Biddle SJ, Nimmo MA CS. Cross-sectional surveillance study to phenotype lorry drivers' sedentary behaviours, physical activity and cardiometabolic health. BMJ Open. 2017;7(6):e013162.

10. Ganguly E, Kumar S. Morbidity profile of long distance truck drivers in Hyderabad city, India. Journal of Dr NTR University of Health Sciences. 2014;3(4):234-7.

11. Kartikeyan S, Gurav RB, Joshi SD WR. Health and Socio Demographic Profile of Transport Workers. Indian Journal of Occupational and Environmental Medicine. 2004;8(2).

12. Amod B, Shubhangi A, Sandeep G, Prashant T. Study of Occupational Factors Associated with Low Back Pain in Truck Drivers of Nagpur City, India. International journal of Medical and Health Sciences. 2012;1(3):53-60.

13. Agrawal K, Agrawal L, Agrawal V, Chaudhary V. Behavior surveillance survey amongst truck drivers regarding HIV/AIDS. Journal of Behavioral Health. 2012;

14. Saidel T, Adhikary R, M. Mainkar, Dale J, Loo V, Rahman M, et al. Baseline integrated behavioural and biological assessment among most at-risk populations in six high-prevalence states of India: Design and implementation challenges. AIDS. 2008;22(5):S17-34.

15. Saberi HR, Moravveji AR, Fakharian E, Kashani MM, Dehdashti AR. Prevalence of metabolic syndrome in bus and truck drivers in Kashan, Iran. Diabetology and Metabolic Syndrome. 2011;3(8).

16. Sieber WK, Robinson CF, Birdsey J, Guang X, Hitchcock EM, Lincoln JE, et al. Obesity and Other Risk Factors: The National Survey of U.S. Long-Haul Truck Driver Health and Injury. American Journal of International Medicine. 2015;57(6):615-26.

17. WHO expert consultation. Appropriate body-mass index for Asian populations and its implications for policy and intervention strategies. The Lancet. 2004;363(9403):157-63.

18. NCD Risk Factor Collaboration, (NCD-RisC). Worldwide trends in body-mass index, underweight, overweight, and obesity from 1975 to 2016 : a pooled analysis of 2416 population-based measurement studies in 128.9 million children, adolescents, and adults. Vol. 390, The Lancet. 2017. 2627-2642 p.

19. Danaei G, Finucane M, Lu Y, Singh G, Cowan M, Paciorek C, et al. National, regional, and global trends in fasting plasma glucose and diabetes prevalence since 1980. The Lancet. 2011;378(9785):31-40.

20. NIH-NLM. SNOMED Clinical Terms ${ }^{\circledR}$ (SNOMED CT ${ }^{\circledR}$ ) [Internet]. NIH-US National Llbrary of Medicine. 2015. Available from: https://www.nlm.nih.gov/research/umls/Snomed/snomed_main_old.html 
21. Association AD. Diagnosis and Classification of Diabetes Mellitus. Diabetes Care. 2010;33(1):S62-9.

22. International Institute for Population Sciences (IIPS) and ICF. National Family Health Survey 4 - India. 2015;

23. IBM Corporation. IBM SPSS Statistics 25 Brief Guide. IBM Corporation. 2011;

24. Goon M, Ghoshal S, Chandrasekaran B, Sharma C. Prevalence of Low Back Pain in Long Distance Truck Drivers of Mountainous Terrain . Advances in Occupational, Social and Organizational Ergonomics, Taylor and Francis Group. 2010;(June).

25. Gupta R, Guptha S, Sharma K, Gupta A, Deedwania P. Regional variations in cardiovascular risk factors in India: India heart watch. World Journal of Cardiology. 2012;4(4):112-20.

26. Pradeepa R, Anjana RM, Joshi SR, Bhansali A, Deepa M, Joshi PP, et al. Prevalence of generalized \& abdominal obesity in urban \& rural India- the ICMR - INDIAB Study (Phase-I) [ICMR - INDIAB-3]. Indian Journal of Medical Research. 2015;142(2):139-50.

27. Shah S, Dave B, Shah R, Mehta TR, Dave R. Socioeconomic and cultural impact of tobacco in India. Journal of Family Medicine and Primary Care. 2018;7(6):1173-6.

28. Thakur JS, Prinja S, Bhatnagar N, Rana SK, Sinha DN, Singh PK. Widespread inequalities in smoking \& smokeless tobacco consumption across wealth quintiles in States of India: Need for targeted interventions. Indian Journal of Medical Research. 2015;141(6):789-98.

29. Porter RJ, Hegmann KT. Commercial Driver Medical Examinations. Journal of Environment Medicine. 2015;57(6):659-65.

30. Apostolopoulos Y, Sonmez S, Shattell MM, Gonzales C, Fehrenbacher C. Health survey of U.S. longhaul truck drivers: Work environment, physical health, and healthcare access. Work. 2013;46(1):11323.

31. Anchala R, Kannuri NK, Pant $\mathrm{H}$, Khan H, Franco OH, Di Angelantonio E, et al. Hypertension in India: a systematic review and meta-analysis of prevalence, awareness, and control of hypertension. Journal of hypertension. 2014;32(6):1170-7.

32. Anjana RM, Deepa M, Pradeepa R, Mahanta J, Narain K, Das HK, et al. Prevalence of diabetes and prediabetes in 15 states of India: results from the ICMR-INDIAB population-based cross-sectional study. The Lancet Diabetes and Endocrinology. 2017;5(8):585-96.

33. Ramakrishnan S, Zachariah G, Gupta K, Shivkumar Rao J, Mohanan PP, Venugopal K, et al. Prevalence of hypertension among Indian adults: Results from the great India blood pressure survey. Indian Heart Journal. 2019;71(4):309-13.

34. Sharma NC. Government survey found $11.8 \%$ prevalence of diabetes in India [Internet]. LIVE Mint. 2019 [cited 2020 Sep 27]. Available from: https://www.livemint.com/science/health/governmentsurvey-found-11-8-prevalence-of-diabetes-in-india-11570702665713.html

35. Ramachandran A, Snehalatha C, Kapur A, Vijay V, Mohan V, Das AK, et al. High prevalence of diabetes and impaired glucose tolerance in India: National Urban Diabetes Survey. Diabetologia. 2001 Sep;44(9):1094-101. 
36. Green R, Milner J, Joy EJM, Agrawal S, Dangour AD. Dietary patterns in India: a systematic review. British Journal of Nutrition. 2016;116(1):142-8.

37. Greenfield R, Busink E, Wong CP, Riboli-Sasco E, Greenfield G, Majeed A, et al. Truck drivers' perceptions on wearable devices and health promotion: A qualitative study. BMC Public Health. 2016;16(677).

38. Saggurti N, Bharat S. Health care coverage among long-distance truckers in India: An evaluation based on the tanahashi model. HIV/AIDS - Research and Palliative Care. 2015;7:83-94.

\section{Figures}

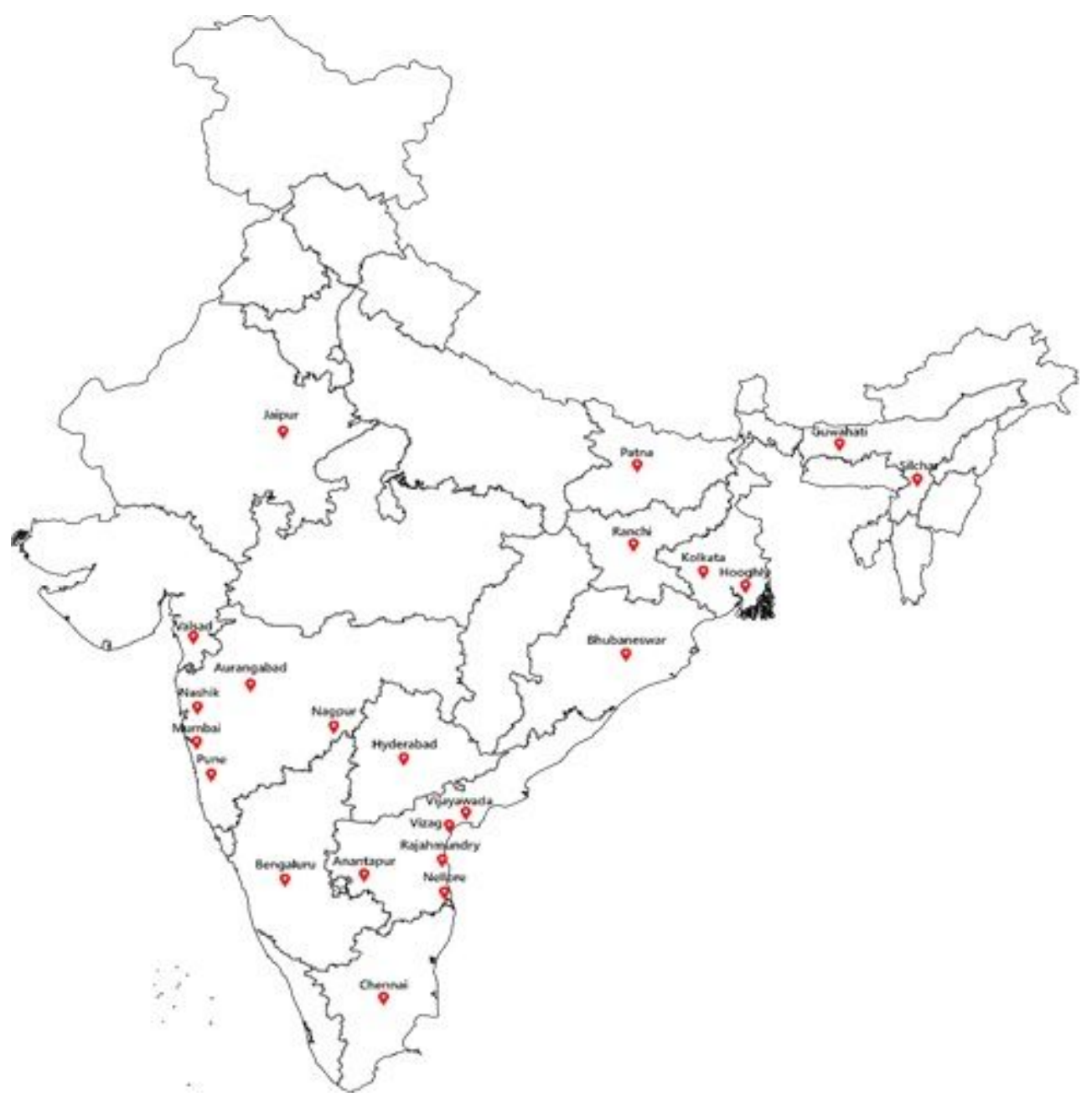

Figure 1

Distribution of "STFC-MMU" Program Sites across Twelve Indian States (2018-2019) 


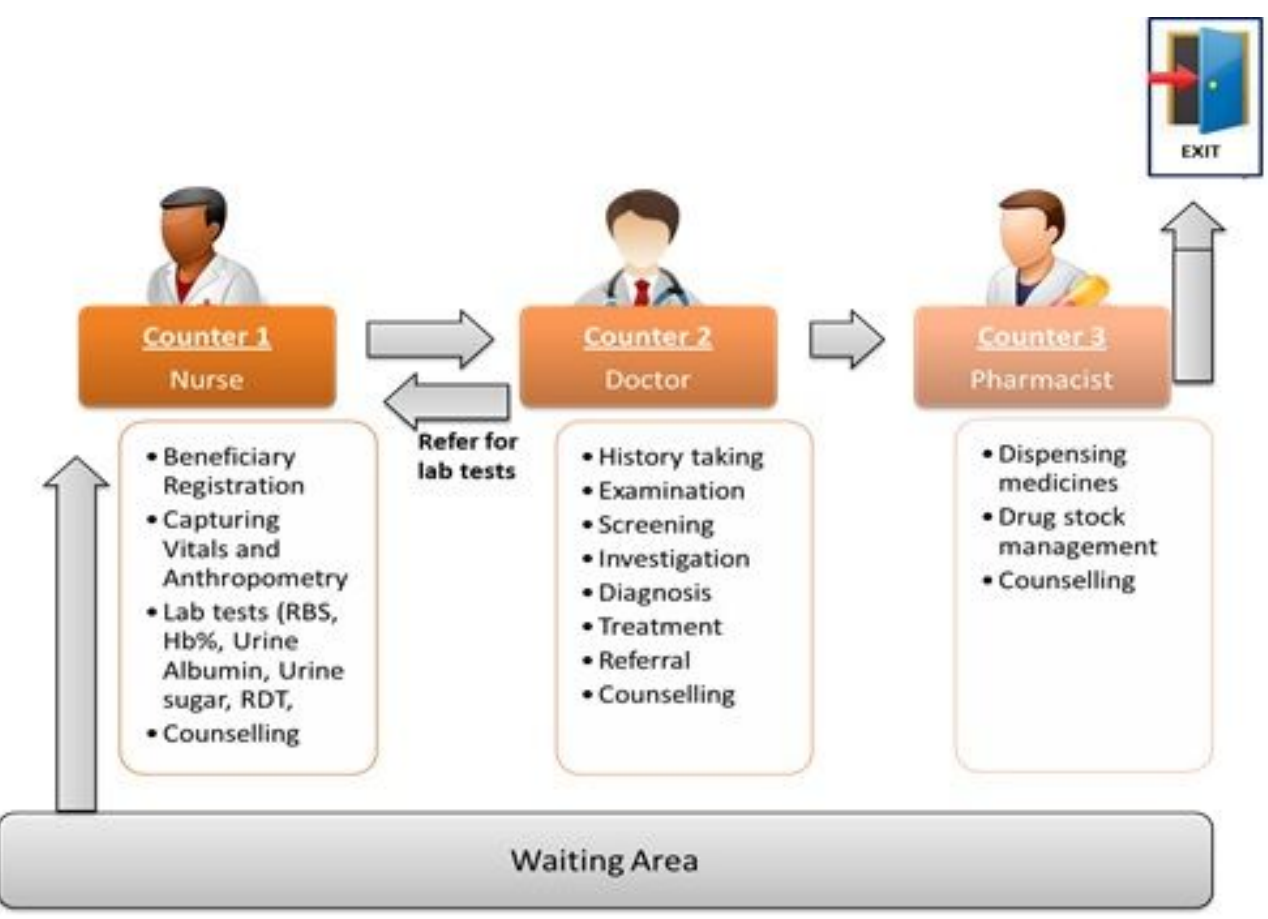

Figure 2

The "STFC-MMU" Program Services Flow

Total extracted records from the STFC MMU database from July 2018 to February 2019: 170883

Removed data records of beneficiaries at their second, third or next visit to MMU:

124662

Retained the data of the beneficiaries who are drivers, within ages of 15 to 75 years and have theoretical possible values of medical metrics value:

54314

Excluded the records with incomplete, blank or erroneous information

Final sample size consists of individual truck driver with information on their 1st visit to MMU

$\mathbf{1 5 7 2 5}$ Unique Health records

Figure 3

Analytical Sample Calculation 